\title{
From the Managing Editor
}

\author{
Gamin Bartle \\ University of Alabama
}

You'll often hear personal accounts from IALLT members about how much the people mean to each other, and how lasting friendships come from meeting fellow IALLTers. I have found this to be the case over and over again. Every time I get together with my regional group, or see IALLTers at conferences, or communicate electronically or on the phone, I am reminded that it is indeed a very special group of people. We help, encourage, and support each other. This is exactly what I wanted for my workinglife. It occurs to me that such helpful people must be drawn to this kind of work, for it is rare indeed that I have heard of such a positive and supportive atmosphere in other realms of working life.

These same friendly, helpful people happen also to be extraordinarily good at their jobs. Exceptional enough, in fact, to spend countless volunteer hours - way above and beyond the call of duty, not to mention beyond what our paychecks might attempt to give back to us-working on and with our regional and international organization. The IALLTStatement of Professional Responsibilities putsinto words much of what we do in a way that people outside the profession can understand. The Statement is proof of our willingness to work together and share ideas with one another, in this case ideas about the very definition of our work.

I've got two ideas that seem incongruent to fit into one column, as a way of sharing what I am in the process of learning with Journal readers. First, I'd like to second Andrew's call for all of you to consider submitting to the Journal. It seems that there are a lot of ideas and projects out there amongIALLT members, butindividuals do not have the time to polish them up for publication. Recently I attended a small but extremely useful SEALLT conference in Miami, and virtually every presentation was worthy of sharing with our full readership and beyond. The term virtually applies only to my own presentation, which leads to my other point.

In my life and work I am studying time management. Far from becoming an instant expert, Isoon learned that there is not enough 
time to read a respectable amount of available materials on the subject. I tried to resist making the obvious jokes about not having time to manage my time, and take a serious look at the issue. Those of you who know me should already realize that I was unable to refrain from the jokes. The serious issues, however, cameout aswell, as I tried to outline and discuss ideas I had found in my reading. You cannot, for example, "manage" time in the wayyou manage other things. You must manage yourself and how you prioritize the spending of an allotted amount of time. I don't have to tell you that an eight (nine? ten?) hour work-day can go very quickly. Prioritization is vital.

It would be great if I could promise to have all of the answers to our time pressure questions formyIALLT presentation. The reality is that mypresentation will be just a bit further down the path toward being more helpful than it was atSEALLT. And maybe this is where my two points can come together in a useful way. At some point, in this case when mypresentation is scheduled, you have to stop and say thatyour idea, your project, or even your manuscript for the Journal is ready enough. The key word here is enough, meaning, of course, that you will be helping your colleagues whether or not your project is "perfect" or "complete."

Of course I am not advocating the submission of substandard work to the Joumal. Instead, I would like to take the opportunity to remind you that the Journal has in place an excellent peer-review and editing process. If your submission is accepted for publication but also found to need revision, you will be notified and receive suggestions from the peer reviewers. It is a great way to get help with your writing, so that your project gets into a professional publication. The Journal readership, of course, benefits as well because the ideas you had been waiting for the time to polish get polished in the editing process. This is a win-win-win situation, foryou, your career, and your colleagues.

I look forward to placing your text into a future issue of the Journal! 